\title{
EL TEIDE EN LA OBRA DE OLIVIA STONE: EL PAISAJE COMO RECURSO TURÍSTICO
}

\author{
Esther Beltrán Yanes \\ Universidad de La Laguna
}

\section{RESUMEN}

El interés por los originales paisajes canarios, con su mejor representación en el Teide, será una de las motivaciones destacadas del despegue turístico del archipiélago a finales del XIX. A partir del acercamiento a la cultura de la alta sociedad británica que inspiraba sus viajes de placer, con un significativo número de turistas en las islas durante esos años, y el estudio del libro de viaje de Olivia Stone (1887), se identificarán las claves que confirman dicha hipótesis y que reafirman la viabilidad del concepto del paisaje como recurso turístico en una nueva etapa madura del turismo en Canarias.

Palabras clave: Tenerife, paisaje, turismo maduro, literatura de viajes, Olivia Stone

\section{Mount Teide in the work of Olivia Stone: landscape as a tourism resource}

\section{ABSTRACT}

An interest in the original landscapes on the Canary Islands, best represented by the Teide, is considered to be another catalyst for the boom in tourism on the archipelago in the late nineteenth century. The keys that confirm this hypothesis and that reaffirm the viability of the concept of landscape as a tourism resource in a new mature stage of tourism in the Canary Islands will be identified based on the introduction to the culture of British high society that inspired their leisure trips, with a significant number of tourists during those years, and from studying the travel stories (1887) narrated by the Olivia Stone.

Keywords: Tenerife, landscape, mature tourism, travel literature, Olivia Stone.

Recibido: 15 de noviembre de 2015

Devuelto para su revisión: 4 de mayo de 2016

Aceptado: 5 de julio de 2016

Departamento de Geografía e Historia. Universidad de La Laguna. Campus de Guajara, 38071 TENERIFE (España).E-mail: estyanes@ull.es 


\section{INTRODUCCIÓN}

El paisaje y la naturaleza de las Islas Canarias destacan mundialmente por su diversidad y originalidad. En un fragmentado espacio insular se combinan variados factores geográficos que configuran multitud de aspectos del territorio en una reducida superficie $\left(7.493 \mathrm{~km}^{2}\right)$. La latitud subtropical de las islas de tránsito entre lo mediterráneo y lo tropical, el diverso efecto de los vientos atlánticos del alisios en unas islas volcánicas montañosas de contrastadas altitudes y topografía, la actividad irregular de los volcanes en el tiempo y el espacio, y por último, la fecunda y sabia capacidad de los canarios para vivir de sus recursos naturales a lo largo de la historia, se entrelazan de forma independiente en cada una de las islas confiriéndoles su valiosa identidad geográfica.

Las singulares características del paisaje y naturaleza de las islas hicieron de este archipiélago objeto de una larga tradición viajera que se intensificó a lo largo del siglo XIX. Las Islas Canarias han sido afortunadas en este aspecto, lo cual no debería perderse de vista cuando se analiza el fenómeno turístico contemporáneo. En concreto, los viajes hacia Canarias tienen unos orígenes lejanos en el tiempo y dieron lugar a una significativa producción literaria en forma de relatos y libros de viaje. El Romanticismo, movimiento cultural que inspira el inicio de los viajes por placer a Canarias, trasladó el viaje fuera de los límites estrictamente europeos y lo llevó a destinos más exóticos y lejanos. El espíritu de aventura e independencia, el sentimiento por encima de la razón, el gusto por lo popular, lo exótico y lo pintoresco, fueron las principales fuerzas de motivación de estos cambios en los destinos y formas de viajar, y dieron lugar a la aparición de nuevos destinos para los viajes de placer en los que comienza a destacar a finales del XIX las Islas Canarias. Hay que recordar además que este archipiélago, aunque localizado relativamente cerca de Europa, se mantuvo muy alejado del desarrollo industrial europeo de la época, conservando por ello intactas fisonomías de su naturaleza y mundo rural, y también vivo el carácter popular y tradicional de sus costumbres. Los puertos marítimos de las islas de Tenerife y Gran Canaria constituyeron durante esa época puntos de obligada escala de las navieras británicas que transportaban acaudalados turistas europeos hacia estas islas en sus rutas marítimas por el Atlántico oriental rumbo América del Sur o hacia las colonias británicas de África.

El trabajo que se presenta tiene, por tanto, un doble objetivo. Por un lado, indagar sobre el interés turístico por el paisaje de Canarias, y especialmente por los de fisonomía predominantemente natural, entre los europeos y en particular entre los británicos a finales del XIX. Y por otro, una vez cumplido este primer objetivo, demostrar que uno de los principales foco de atracción en este sentido era el excepcional escenario asociado al imponente estratovolcán del Teide.

Para llevar a cabo este doble objetivo ha sido imprescindible realizar en primer lugar un breve acercamiento a la cultura europea de la alta sociedad británica que inspiraba los viajes de placer y ratos de ocio en la naturaleza y el campo durante esa época, y posteriormente, analizar los relatos de aquellos viajeros que visitaron las islas atraídos por el paisaje y que tuvieron una importante función en el despegue del turismo durante aquellos años. En esta última fase del trabajo se parte de una breve caracterización de los rasgos más sobresalientes de los paisajes del Teide, para demostrar a través del análisis del libro de viaje de la británica Olivia Stone, que esta autora, fascinada por el Teide, lleva a cabo 
el descubrimiento de esta excepcional montaña por medio de unos criterios de percepción que presentan sorprendentes coincidencias con el reconocimiento geográfico del paisaje.

\section{EL PAISAJE COMO RECURSO TURÍSTICO}

El significado de paisaje como forma de conocimiento científico se centra en el estudio de la fisonomía del territorio y, con ello, en la explicación del conjunto de formas y elementos que lo integran. Este concepto implica la totalidad de todos los componentes del paisaje, tanto naturales como culturales, la búsqueda de las relaciones que se producen entre ellos y su plasmación espacial (Martínez de Pisón, 2009a; Beltrán, 2000; Bertrand, 2006). Esta definición científica del concepto de paisaje permite advertir su plena convergencia como objeto de estudio a la Geografía, pues esta disciplina centra su estudio en la caracterización de los territorios, de ahí que desde hace tiempo se conozca también a la Geografía como la Ciencia del Paisaje. El estudio del paisaje conlleva, por tanto, no solo la visión global del territorio en sus componentes naturales (relieve, vegetación y suelo), sino también de la cultura de quienes lo han habitado y lo habitan, pues como señala el profesor Martínez de Pisón (2009b:38) "su análisis debe reunir también toda la información de las diferentes "miradas" de quienes los han configurado, lo que requiere la recogida no sólo de las contemporáneas y simultáneas, sino también las de las distintas épocas que lo han vivido o hasta construido".

Nunca hasta ahora, el paisaje había sido tan valorado por la sociedad, en la medida en que es una referencia existencial para todo ser humano y, también, en la medida en que los individuos y los diferentes grupos sociales le conceden ciertos valores y lo han convertido en un bien estratégico, objeto de regulación y legislación muy variada. Durante las últimas décadas, con el implacable avance y desarrollo de los modos de vida urbanos y la cultura del ocio en los países occidentales, junto con la importancia que ha obtenido el discurso ecologista, se ha ido consolidando la valoración de los paisajes, sobre todo de los que corresponden a fisonomías fundamentalmente naturales o expresivas de modos de vida rural en equilibrio con los recursos propios de ese territorio. En consecuencia, el paisaje es cada vez más considerado como un bien común, un "capital” cuya rentabilidad social y especialmente económica es innegable. Pero su valor aumenta además si se lo contempla como recurso turístico, pues el turista de hoy es menos homogéneo, más informado, más exigente y desea visitar entornos auténticos y con personalidad geográfica. El conocer otros paisajes, otras fisonomías diferentes a las habituales, acercarse a ellas y disfrutar de su descubrimiento está constituyendo ahora una motivación novedosa de los desplazamientos por turismo (Gros, 2002).

Aunque es innegable la valoración social mayoritaria que tiene el paisaje en la actualidad y las valiosas perspectivas que posee como recurso turístico en una nueva etapa madura, resulta muy llamativo cuando se rastrean los orígenes del turismo en Canarias a finales del s. XIX, descubrir cómo el interés por el paisaje como recurso turístico se percibe desde el inicio del mismo entre los extranjeros europeos que visitaban Canarias por aquella época.

Según Nogué (1989), el turismo se entiende como un complejo conjunto de relaciones y fenómenos que se derivan de los desplazamientos y las estancias temporales en un lugar 
determinado, por parte de gente que proviene de otro lugar y que viaja por motivos recreacionales o de placer. Por ello, el viaje es una experiencia geográfica que se desarrolla a partir de dos lugares concretos que lo fundamentan, y que corresponden al lugar de origen y el punto de destino, dándose entre ellos una interacción espacial que en pocas ocasiones se analiza globalmente. Este autor añade que por lo general la mayoría de los estudios se refieren sólo a una de esas referencias, predominando los centrados en el punto de destino y son escasos los estudios que han intentado explícitamente poner en relación las regiones y la cultura de origen con las áreas receptoras, analizándolas con detalle. A partir de este acertado planteamiento metodológico, resulta imprescindible por tanto acercarse aunque sea sucintamente al contexto cultural social de la élite británica que condicionaba la elección de los destinos de sus viajes de placer por aquella época e impregnaba alguna de sus principales aficiones en sus ratos de ocio con especial atención en el contacto con la naturaleza. Sólo a través de esta primera fase del trabajo se podrán esclarecer las causas del significativo cambio de interés de una destacada proporción de turistas de esta alta sociedad, que dirigió a partir del último cuarto del XIX su atención hacia las cálidas y exóticas islas del sur.

\section{EL INICIO DEL ATRACTIVO TURÍSTICO DE LAS ISLAS CANARIAS EN EL S. XIX}

Efectivamente, en la segunda mitad del s XIX, una vez finalizadas las guerras napoleónicas y la paz en los mares, la alta sociedad europea, y en particular la británica, recupera la tradición de los viajes con la novedad que se traspasan las fronteras cercanas del viejo continente europeo. Parte del turismo invernal que se llevaba a cabo en los lugares más cálidos de Europa, concretamente en el Mediterráneo, se trasladó a partir del último cuarto de siglo a zonas más alejadas del continente situadas en el Atlántico oriental como la isla de Madeira y el archipiélago canario y, fundamentalmente en éstas últimas, hacia el Puerto de la Cruz de Tenerife y Las Palmas de Gran Canaria. Aquella sociedad decimonónica extranjera que visitaba las islas, principalmente de origen inglés, prefería ahora las estancias de reposo junto al mar y demandaba otros destinos turísticos muy diferentes a los tradicionales europeos. No obstante, sus viajes seguían asociándose a costumbres y modos de vida dirigidos a la búsqueda del bienestar, envueltos siempre en un ambiente selecto. Era una huida de Gran Bretaña, sobre todo durante la estación invernal, justo cuando las temperaturas alcanzan sus valores medios más bajos, entre $0^{\circ}$ y $5^{\circ} \mathrm{C}$, y la atmósfera de Londres se hacía irrespirable por la elevada humedad ambiental y la densa niebla.

La prosperidad económica que vivió Inglaterra durante el XVIII y XIX trajo consigo un elevado crecimiento de la ciudad de Londres que ya a finales del XIX se acercaba a los cinco millones de habitantes -4.766.661 en el año 1881- (Howarth, 1911). La intensificación del smog o smoggy air, una niebla espesa que cubría las ciudades industriales, mezcla de humo (smoke) contaminante y la neblina (fog) procedente de la evaporación del Támesis, favorecía la huída de las clases altas de la capital británica.

Las clases dominantes se quejaban de la contaminación de Londres y también manifestaban una evidente predisposición a sufrir trastornos patológicos por las adversas condiciones ambientales urbanas que contribuían a estados de melancolía o depresión conocidos por la palabra inglesa splen (González Lemus et al., 2012). Médicos y escritores ingleses 
de la época recomendaban para combatirla el contacto con la naturaleza, la respiración del aire puro y las estancias en el campo. Por tanto, la élite inglesa solía trasladarse al campo durante temporadas a vivir en sus amplias y confortables residencias, donde podía disfrutar del paisaje y la vida campestre. Las elegantes casas aisladas con bellos jardines y espacios abiertos que permitían gran luminosidad y aire de mejor calidad, serían a partir de entonces inseparables del gusto de la aristocracia por el campo. El disfrute del paisaje a través de paseos por el bosque, el campo o el río próximo, facilitaban el contacto con la naturaleza y valiosos ratos de tranquilidad y sosiego, muy alejados del apretado ritmo urbano y de sus ambientes enrarecidos industriales tan contraproducentes para la salud física y mental.

Modos de vida inspirados en estas ideas se pueden reconocer en los personajes de la literatura de la época como los de célebre escritora inglesa Jane Austen o, desde el punto de vista artístico, en los pintores del XVIII y XIX adscritos al movimiento romántico, fuertemente atraídos también por los paisajes naturales. Las bellas pinturas de sus paisajes enriquecidas por creativas tonalidades de luz y geniales atmósferas como los de Turner o Constable, son expresivos también de este poderoso interés artístico por la naturaleza.

Pronto estos gustos serían asumidos por la burguesía adinerada y constituirían uno de los valores culturales más sobresalientes de la élite británica de la época: el culto a los paisajes naturales. Este lifestyle, conservado hasta la actualidad en la alta sociedad británica, enlaza directamente con el estilo del turismo de calidad que se va a desarrollar en Canarias durante el s. XIX y principios del XX, y más concretamente en la isla de Tenerife, en el valle de La Orotava, con el Pico del Teide coronando de forma espléndida sus cumbres montañosas (Figura 1).

No hay que olvidar, además, que por aquella época el viaje por motivos de salud tenía también una gran relevancia debido a los elevados índices de mortalidad por la tuberculosis y otras enfermedades, que las bajas temperaturas invernales y la humedad, propios del clima oceánico europeo, no ayudaban a combatir. Por ello, empezó a considerarse como beneficiosas aquellas áreas geográficas con climas más cálidos. Las islas de la costa occidental de África, preferentemente Madeira y Canarias, cercanas al continente europeo, fueron destacadas como lugares recomendables para la salud por las propiedades benignas de su clima. Por todo ello, con el desarrollo de nuevos centros médicos-turísticos, los destinos canarios y fundamentalmente Tenerife con el Pico del Teide como gran atractivo turístico, constituyó un primer lugar de establecimiento. Las nuevas clases surgidas en la era de expansión económica, ansiosas de mejorar su estatus social, se trasladaron a los nuevos health resort de estas islas subtropicales. En esos lugares se combinaban los beneficios para la salud a través del contacto con la naturaleza por medio de tranquilos paseos por el campo y baños de mar, con el disfrute del descubrimiento de la belleza y el exotismo de los paisajes isleños.

En consecuencia, los nuevos centros turísticos no sólo serían deseados y frecuentados como remedio para los convalecientes, sino también por la simple novedad o cambio de ambiente asociado a una nueva forma de obtener emociones y experiencias de la aristocracia europea, y que muchos burgueses en su afán de emular la forma de vida de la alta sociedad, adquirieron rápidamente.

Entre los visitantes extranjeros que comenzaron a llegar al archipiélago canario existían, además de los viajeros que venían a las islas por salud o para descansar, otros 
cuya estancia respondía principalmente a su interés por recorrer las islas para conocer el gran volcán y sus originales paisajes. El objetivo de su visita era viajar por las islas en busca de lo más pintoresco de Canarias, sus paisajes más representativos, conocer sus costumbres y hechos históricos más relevantes y, en muchas ocasiones, sus recorridos se llevaban a cabo con bastantes dificultades. Este viajero podía llevar un cuaderno de notas para describir aquellos aspectos que le resultaban más interesantes y registrar además sus emociones e impresiones. Con sus cuadernos, cartas y escritos fueron creando una literatura de viaje de gran importancia para el conocimiento de la historia social y de los antiguos paisajes insulares, pero también muy útil para rastrear las motivaciones y preferencias que distinguían sus viajes (González Lemus, 1998).

El número de viajeros de estas características que visitaron nuestras islas por aquellos años fue significativo y destacan, entre otros, William Hadfield, John Whitford, Charles Edwardes, Harold Lee, Lady Brassey, Olivia Stone, J.H.T. Ellerbeck y Alfred Samler Brow. Este último fue el editor de las guías turísticas más conocidas y utilizadas por los británicos que visitaban las islas de Tenerife y Gran Canaria por aquellos tiempos. Entre los viajeros aventureros que vinieron a Canarias llama la atención Richard Francis Burton (1821-1900), quizás el explorador más renombrado de esta época que junto a John Hanning Speek realizó la célebre expedición en busca de las fuentes del Nilo. Pero si para los ingleses Richard Francis Burton pudo ser el principal viajero aventurero de la época victoriana por sus célebres viajes a África, para Canarias la viajera aventurera más sobresaliente de este tiempo fue Olivia Stone. Es la única viajera que durante una prolonga visita a Canarias penetra en los lugares más alejados de las siete islas para descubrir la geografía del archipiélago. Los Stone -Olivia vino acompañada de su marido John Harris- pueden ser considerados además de viajeros, los auténticos exploradores de Canarias, si la imagen tradicional del explorador representaba a alguien que llegaba a los lugares más recónditos que ningún viajero extranjero había visitado antes, después de superar las más variadas incomodidades durante sus viajes y realizar arduos esfuerzos para alcanzar su ansiado objetivo. La publicación del cuaderno de viaje de Olivia Stone constituyó uno reclamo turístico de primer orden de las Islas Canarias para la sociedad británica de la época (Riedel, (1972).

\section{Figura 1 \\ EL TEIDE SOBRE LAS CUMBRES NORORIENTALES DE LA ISLA DE TENERIFE}

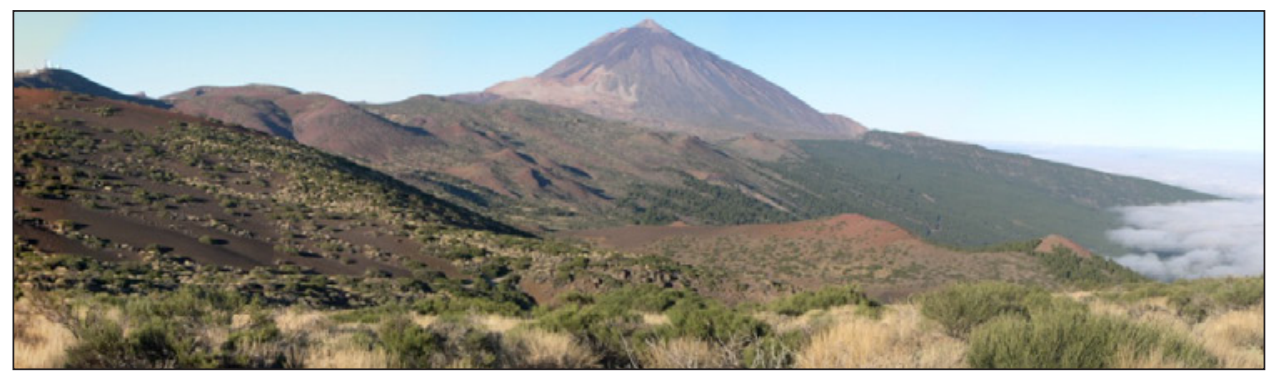

Fuente: autora. 
El comienzo del turismo en Canarias tuvo lugar en el Valle de La Orotava y, en concreto, en el la localidad costera del Puerto de la Cruz y varias fueron las razones. En primer lugar la incidencia del marco natural. Si bien el clima fue un factor importante en los comienzos del turismo en las islas, el paisaje fue un elemento clave para su elección. La costa de La Orotava tenía esa playa que tanto ansiaba el británico y el europeo en general de finales del XIX, no para tomar el sol sino para disfrutar a través de paseos o discretos baños en el mar. Pero además, La Orotava ofrecía un paisaje excepcional con fundamentos naturales muy atractivos para el turista europeo: el impresionante estratovolcán del Teide con su cima a $3.718 \mathrm{~m}$ sobre el nivel del mar coronando con gran belleza las cumbres de la isla. El Teide configuraba una montaña imponente con un sorprendente paisaje volcánico subtropical que sólo los turistas más intrépidos con espíritu de aventura se atrevían a visitar (Villalba, 1999). Era el centro de atracción de Tenerife que fascinaba a los visitantes y como bien expresó el ilustre médico británico John Cleasby Taylor "el escenario del Valle de La Orotava nunca está completo sin sus grandiosas vistas” (Cleasby,1889:15). Esta alternativa turística principal se completaba con excursiones por otros llamativos paisajes de las islas, visitas a las ciudades más relevantes de Tenerife, y agradables ratos de ocio que ofrecían los primeros hoteles de lujo y clubs británicos, abriéndose paso una nueva manera de entender el entretenimiento y disfrute turístico. La propia Olivia Stone comentaría que "todo su conjunto, su posición, su clima, sus alrededores, sus residencias, la sociedad, las conveniencias y, sobre todo, la proximidad del Teide, hacían del Valle de La Orotava el centro más adecuado en el archipiélago como residencia para extranjeros" (Glez. Lemus et al., 2012:87).

Así pues, a finales del XIX se constituyó la primera empresa turística de Canarias: "La Compañía de Hoteles y Sanatorium del valle de La Orotava" para el establecimiento de un hotel de primera clase en el Valle de La Orotava. El primer hotel se estableció en los Llanos de Martiánez y era una casa de estilo colonial inglés, recomendada también por Olivia Stone como la mejor residencia en el lugar, aunque con el objetivo posterior de construir un hotel con todas las comodidades y adelantos modernos en la llanura del promontorio de la Paz. Este hotel se denominó Orotava Grand Hotel o también llamado Hotel Martiánez, inaugurado oficialmente el 12 de septiembre de 1886. Llama la atención y tiene un alto significado para nuestra hipótesis de trabajo que su acta de inauguración resalte como gran reclamo turístico paisajes de la isla de Tenerife tan llamativos y singulares como los de la costa y pueblo de Garachico, al pie de acantilados de $500 \mathrm{~m}$ de altura, o el angosto valle de Taganana rodeado de espectaculares relieves acastillados labrados en antiguas montañas volcánicas, al norte de Tenerife. Acompañaban a estas imágenes la del profundo barranco de Adeje con sus atractivos saltos de corrientes de agua, al sur de la isla y, por supuesto, diversas panorámicas del volcán del Teide sobre el valle de La Orotava.

En este sentido, también es muy revelador analizar los contenidos de la guía turística de Alfred Smaler Brown que tuvo una destacada función en el inicio del turismo en las islas durante esos años. La guía Madeira, the Canary Islands and Açores. A Complete Guide for the Use of Invalids and Tourists se publicó por primera vez en el año $1889 \mathrm{y}$ fue récord de ventas, experimentando sucesivas reediciones revisadas que superaron las quince impresiones hasta 1935, con una media de dos mil ejemplares en cada edición (González Cruz, 2000). Esta obra contiene variados itinerarios para conocer las islas, 
sus principales ciudades, pueblos y enclaves arquitectónicos y culturales más relevantes, y es muy significativo desde el punto de vista del turismo de naturaleza y paisaje, la atención que presta a los rasgos exclusivos del relieve, clima y vegetación de las islas (con detalladas figuras y cuadros) y, por supuesto, al volcán Teide. La guía dedica a este volcán comentarios destacados y ofrecía diversas rutas de ascenso a Las Cañadas en las que se señalaban, incluso, aquellos lugares en los que se podían disfrutar de las mejores contemplaciones de este sector cimero de Tenerife. Para llevar a cabo los recorridos por las islas se hacían las pertinentes recomendaciones sobre ropa de abrigo e impermeables, botas adecuadas y bastones, éstos últimos imprescindibles para las caminatas en las cumbres más altas de Tenerife (Samler Brown, 2000 [ed. orig. 1919]). Tal como indica la profesora de Filología Inglesa de la Universidad de Las Palmas, Isabel González, en la introducción de la reciente edición de esta guía en español: "la guía Brown se convertiría en uno de los manuales de obligada adquisición para cualquiera de los miles de visitantes que recalaban tanto en Canarias como Madeira, y en menor media en las Azores. Se puede decir que esta obra marca un hito en el devenir de la historia insular pues, sin duda, para el turismo de Canarias hay un antes y un después de la Guía” (González Cruz, 2000: 25).

\section{LA VIAJERA VICTORIANA OLIVIA STONE}

El cinco de septiembre de 1883 llega a Santa Cruz de Tenerife la viajera y escritora inglesa Olivia Stone acompañada de su marido John Harris Stone. Su propósito es recorrer y conocer las siete Islas Canarias, objetivo que no había realizado ningún extranjero antes y contar su aventura, observaciones y reflexiones en un libro que finalmente se editará en dos volúmenes.

Stone viaja por las Islas Canarias durante seis meses y utiliza los más variados medios de transporte para realizar su aventura; se traslada a lomos de un caballo, una mula e incluso de un camello, cuando quiere acceder a los lugares más alejados e inaccesibles; utiliza la goleta o el vapor para desplazarse entre islas y, finalmente, el automóvil o "carraca" para recorrer los pueblos y ciudades de las comarcas más prósperas de las islas. Durante las travesías, y sobre todo antes de retirase a descansar, anota lo más fielmente posible todo lo que observa y lo que le acontece, intentando ser lo más objetiva posible en su descripción e interpretaciones. La última redacción de su trabajo incluye información detallada sobre los paisajes, naturaleza, historia, costumbres y pueblos de Canarias, añadiendo en la edición final dibujos, mapas y grabados que ilustran sus recorridos. Todo su trabajo transmite fielmente el espíritu romántico de la aventura del descubrimiento de los paisajes y la cultura de las exóticas Islas Canarias. La primera edición de su cuaderno de viajes se producirá en el año 1887 con el título Tenerife and Its Six Satellites (Tenerife y sus seis satélites) (Amador, 2005).

Esta visión que identifica al Pico Teide con la isla de Tenerife tiene una gran tradición histórica en la literatura de viajes y cartografía de la islas, y el hecho de que los navegantes a medida que se aproximaban a las islas otearan el horizonte en busca de la gigantesca mole del Teide como prueba de la cercanía de éstas explica la percepción del gran estratovolcán como elemento central del archipiélago canario. La visión de Stone de 
las otras islas circundando el Teide es lo que le lleva a describirlas como "satélites" del "planeta Teide" de Tenerife, sin los matices políticos de rivalidades interinsulares locales que posteriores lecturas interesadas puedan haberle dado.

Con respecto al trabajo de Olivia Stone existe, además, una significativa discusión entre los especialistas si puede ser calificado como libro de viajes o guía. Nuestro propósito aquí no es resolver esta cuestión sino destacar a esta viajera de finales del XIX y su trabajo como una buena representación del turista de calidad con inquietudes culturales que podría identificarse hoy en una nueva etapa madura del turismo en Canarias, superado el agotado modelo de sol y playa del pasado siglo (Hernández y Santana, 2010). Autores como Riedel (1972) y González Cruz (2000) han destacado las aportaciones decisivas de las guías Brown y del libro de viaje de Olivia Stone en el aumento de turistas en las islas durante esta época. Según dichos autores, gracias a estas dos publicaciones, las Islas Canarias fueron conocidas por primera vez en amplios círculos de la población europea, principalmente en Inglaterra. Sin embargo, para nuestra hipótesis, el libro de viaje de Stone presenta el valor añadido de que a través del análisis de sus textos personales y detallados se puede comprobar la forma de percibir y reconocer el paisaje de las islas.

En efecto, el libro de viaje de Stone refleja una exquisita sensibilidad cultural que se fundamenta, entre otros intereses intelectuales de la autora, en un extraordinario interés por descubrir el paisaje de las islas considerando, además de su configuración global, sus calidades territoriales. La autora supo trasmitir de forma brillante la experiencia directa del descubrimiento del paisaje convirtiéndola en una vivencia multilateral que revelaba no sólo la originalidad del paisaje que contemplaba, sino también sus valores culturales añadidos. Es indudable que su forma de mirar y comunicar hizo de su cuaderno de viaje una fuente de inspiración de la imaginación de sus lectores, potenciales turistas británicos atraídos por las Islas Canarias.

La publicación Tenerife and its Six Satellites se convirtió en una obra de referencia para hacer turismo en el archipiélago canario y tuvo como objetivo suministrar a la sociedad británica de buena posición social todo lo necesario para pasar un agradable y pintoresco tiempo de viaje en las islas. Así lo señaló el Morning Advertiser y comentarios similares se reseñaron en las publicaciones británicas del Observer, Spectator Graphic, Saturday Review, etc. Su trabajo fue calificado asimismo por algunos medios periodísticos ingleses del momento como pionero del "viaje excursionista" de su tiempo. No cabe duda que su libro de viaje tuvo muy buena acogida entre el público británico pues implicó varias ediciones de su publicación (González Lemus et al., 2012).

Como ya se ha indicado, el deseo de conocer la isla de Tenerife suponía una visita obligada al volcán del Teide y, como es lógico, lo sigue constituyendo en la actualidad, declarado muchos años después Parque Nacional en el año 1954 y Patrimonio de la Humanidad de la UNESCO en el 2006 (Durban y Reverón, 2011). La ascensión al Teide tenía por aquellos años una excepcional fuerza de atracción para los viajeros, pues la conquista de la cima se había convertido en una llamativa moda aventurera. El ascenso a la montaña simbolizaba para los viajeros de inspiración romántica el reto por excelencia de superación personal. Por tal razón todos padecían la "picomanía", como lo llamó la pintora inglesa del XIX, Elizabeth Murray, que vivió una larga temporada en las islas (Murray, 1859). Como cabía de esperar, Olivia Stone tenía también como primordial objetivo ascender a su ele- 
vado pico, pero además, como otros turistas de la época, disfrutar con el descubrimiento y la contemplación de los bellos paisajes de las cumbres más altas de Tenerife. Por tanto, para la consecución del principal objetivo de este trabajo se ha escogido del cuaderno de viaje de esta viajera victoriana para su estudio, el texto que describe su visita al gran volcán.

\section{LOS PAISAJES DEL TEIDE}

Los paisajes del Parque Nacional del Teide destacan por la originalidad geográfica general de una montaña volcánica árida subtropical a la que se suma su originalidad en la región canaria, y a estas excepcionalidades se le añade, además, sus especiales configuraciones internas. En pocos lugares del mundo el relieve volcánico ofrece la cantidad de matices, materiales, formas y estructuras en un espacio de tan escasa superficie como en el Parque Nacional del Teide. El sistema volcánico de Las Cañadas-Teide está ubicado en una posición central del archipiélago canario, situado en la isla de Tenerife y en las cotas altitudinales más altas del conjunto insular, por encima de $2.000 \mathrm{~m}$ de altitud hasta el valor máximo de $3.718 \mathrm{~m}$ sobre el nivel del mar.

Pero, la diversidad de elementos en el paisaje es visible no sólo en una visión de conjunto con la definición de las grandes unidades volcánicas que corresponden al antiguo edificio de Las Cañadas, conocido en la actualidad como el Atrio y que coincide con una extensa caldera volcánica, y al gran estratovolcán doble del Teide-Pico Viejo, sino también en observaciones de detalle, donde a toda una serie de elementos volcánicos (domos, agujas, conos, cráteres, coladas en bloques, cordadas, tubos, jameos, canales lávicos etc.), hay que unir las derivadas de su desmantelamiento erosivo (torrentes, llanos endorreicos, abanicos aluviales, etc.).

Las condiciones climáticas semiáridas que imponen la altitud y su localización en el margen oriental oceánico dan a esta montaña canaria un paisaje definido contundentemente por las formas de relieve, ya que la cubierta vegetal presenta una importancia paisajística relativa, pues contribuye escasamente a la fisonomía general de este espacio. Sobre estas formas de relieve se desarrolla un matorral abierto cuyo aspecto está condicionado por las condiciones ambientales propias del Alto Tenerife y su composición florística determinada, aunque de un modo menos perceptible, por su localización latitudinal.

En efecto, el matorral de esta alta montaña no resta protagonismo a las formas de relieve sino que al contrario, a través de sus diferentes grados de continuidad y recubrimiento, así como de sus variadas combinaciones de especies florísticas, pone énfasis en los rasgos geomorfológicos, resaltando y ayudando a definir la geografía de las formas de relieve. Diferentes combinaciones de la flora propia de esta alta montaña caracterizan formas y ambientes concretos, pero por sus propias dimensiones, por su abundancia, por su capacidad de adaptación a variadas situaciones ecológicas o bien por su originalidad morfológica y cromática, las que tienen una mayor impronta paisajística son la retama (Spartocytisus supranubius), la hierba pajonera (Descurainia bourgaeana), el rosalillo de cumbre (Pterocephalus lasiospermus), el codeso (Adenocarpus viscosus) y los tajinastes (Echium wildpretii y Echium auberianum). Sin embargo, son las formas de relieve las que determinan fundamentalmente la geografía de los tipos de paisaje vegetal del Parque Nacional, desde el denso matorral pluriespecífico hasta las paredes rocosas sólo pobladas 
por ejemplares dispersos de cedros (Juniperus cedrus), pinos (Pinus canariensis) y moralitos (Rhamnus integrifolia). La contundencia de las formas de relieve como condicionantes del paisaje vegetal sólo se ve interrumpida allí donde el hombre creó una cubierta vegetal con un recubrimiento y una coloración paisajísticamente excepcionales, debido a la concentración de elementos arbóreos -Pinus canariensis- (Martinez de Pisón et. al, 2011).

La asociación tan estrecha que hoy se observa entre los componentes morfológico y vegetal del paisaje se ha ido incrementando desde que la declaración de este espacio como Parque Nacional supuso la supresión del aprovechamiento ganadero. La coincidencia de la visión de los viajeros y científicos de los siglos XIX y XX respecto a la existencia de una escasísima cubierta vegetal constituida casi exclusivamente por el retamar, así como la evolución de la que han sido testigos los caminantes habituales del parque, nos indican que en los últimos sesenta años ha tenido lugar una progresiva ocupación biológica, en cuyo proceso se han ido perfilando una gran diversidad de hábitats y de nichos ecológicos que aún no han terminado de definirse. Como ya se ha señalado con anterioridad, en este paisaje se distinguen tres unidades principales que son el antiguo edificio de Las Cañadas, que se presenta configurando un amplio escarpe montañoso de una disposición groseramente circular, el Atrio, que corresponde a una amplia caldera volcánica, y el estratovolcán gemelo del Teide-Pico Viejo.

\subsection{El edificio Cañadas}

Se trata de una amplia construcción volcánica anterior a la formación de la Caldera de Las Cañadas, cuyos restos sólo son visibles en el dorso de La Pared y en el escarpe arqueado que se desarrolla en el sector meridional del parque nacional, cuyos materiales más antiguos se remontan unos 3,5 Ma (Ancochea et al, 1999). Sus paisajes corresponden a viejos edificios demolidos hasta su raíz que presentan atractivas formas desmoronadas y en ruinas, que conviven armónicamente con las morfologías volcánicas recientes a través de un espacio de transición que es el Atrio de las Cañadas (Figura 2). Esta es la otra montaña del sector cimero de Tenerife, aunque tiene la originalidad de que los variados paisajes que encierra se relacionan, en este caso, con otros procesos creadores de formas de relieve radicalmente diferentes al estratovolcán Teide-Pico Viejo como es el del modelado y la erosión. Aquí, La Pared corta las estructuras volcánicas por lo que el paisaje de este sector tiene el valor de desvelarnos los capítulos más antiguos de la historia de este territorio (Martínez de Pisón et al., 2009).

Los espectaculares escarpes de la Pared se han formado como consecuencia de la destrucción del antiguo edificio culminante de Las Cañadas. Parte de la historia de este conjunto volcánico ha desaparecido bajo la acción de procesos tectovolcánicos o ha quedado desdibujada tras la intervención de la erosión.

Los elementos morfológicos que definen al amplio escarpe de Las Cañadas, son, básicamente, siempre los mismos: cejos culminantes de rocas masivas o fragmentadas labrados en las raíces del viejo edificio, taludes y barranqueras alternantes, tapizando su base; localmente junto a estos elementos pueden incluso observarse formas relictas derivadas de situaciones climáticas pasadas de mayor frío, como pequeños nichos de nivación, coladas de piedra, etc. 


\section{Figura 2 \\ IMAGEN DE LAS CAÑADAS OCCIDENTALES CON LAS UNIDADES DE LA PARED Y EL ATRIO}

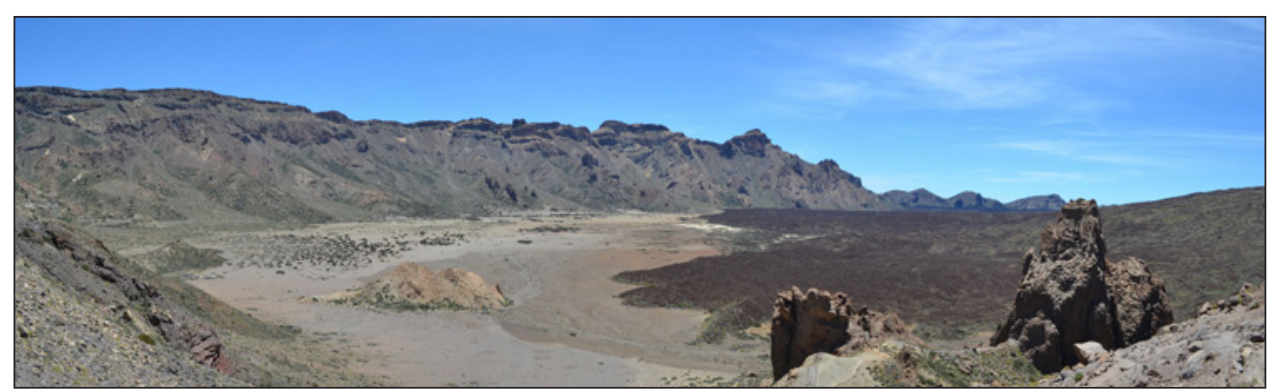

Fuente: autora.

Desde el punto de vista de su paisaje vegetal, a lo largo de la pared de Las Cañadas, La Fortaleza y Los Roques se distingue una geografía de la vegetación que se define, sobre todo, por el apretado ritmo espacial de la alternancia de vegetación rupícola, matorral abierto de Spartocytisus supranubius y matorral cerrado y pluriespecífico, expresiones vegetales que consideradas de modo independiente sólo tienen entidad paisajística a escala de mucho detalle. Las variaciones del sustrato volcánico constituyen el principal factor organizador de la geografía de la vegetación de este sector.

\subsection{El Atrio}

A pesar de que el Atrio constituye una de las grandes unidades morfológicas que caracterizan al relieve volcánico del Parque Nacional del Teide, por cuanto constituye un sector deprimido entre la Pared y el Teide-Pico Viejo, su morfología interna está profundamente vinculada tanto a los procesos volcánicos generados en el estratovolcán como a los procesos de erosión que han marcado la historia más reciente de la imponente pared de Las Cañadas (Figura 3). De este modo, los elementos morfológicos que caracterizan al amplio atrio de Las Cañadas son, por un lado, los llanos de acumulación sedimentaria que flanquean de forma más o menos continua la base inferior de la pared de Las Cañadas, y de otro, las coladas de lava que procedentes del Teide y de Pico Viejo se adentran en la depresión y redibujan de modo constante su morfología de detalle.

Quizás por ello, es precisamente en el Atrio donde la diversidad de formas, procesos, texturas y colores es más amplia. A caballo entre el mundo de lo volcánico y el de la erosión, entre entre el estratovolcán y La Pared de Las Cañadas, y pese a su menor impacto visual, el Atrio debe ser considerado como una de las unidades de relieve emblemáticas del Parque. Es aquí, además, donde la acción del hombre ha sido mayor; no en vano es su carácter deprimido, entre el mundo escarpado de la pared y el mundo de la alta montaña del Teide, así como su apertura natural al norte, al sur y al oeste lo que ha propiciado el que pueda considerarse como una vía de tránsito para de los isleños entre el fértil norte y el árido sur de la isla. Es aquí también, donde los antiguos pobladores 
de la isla -los guanches- establecieron sus pastos de verano y donde, en toda lógica en la actualidad, se desarrollan las principales rutas y senderos turísticos existentes en el interior del Parque.

\section{Figura 3 \\ PANORÁMICA DEL ATRIO ORIENTAL. AL FONDO, LA PARED \\ DEL VIEJO EDIFICIO CAÑADAS Y EN LA BASE, EL ATRIO RELLENO POR DERRAMES LÁVICOS}

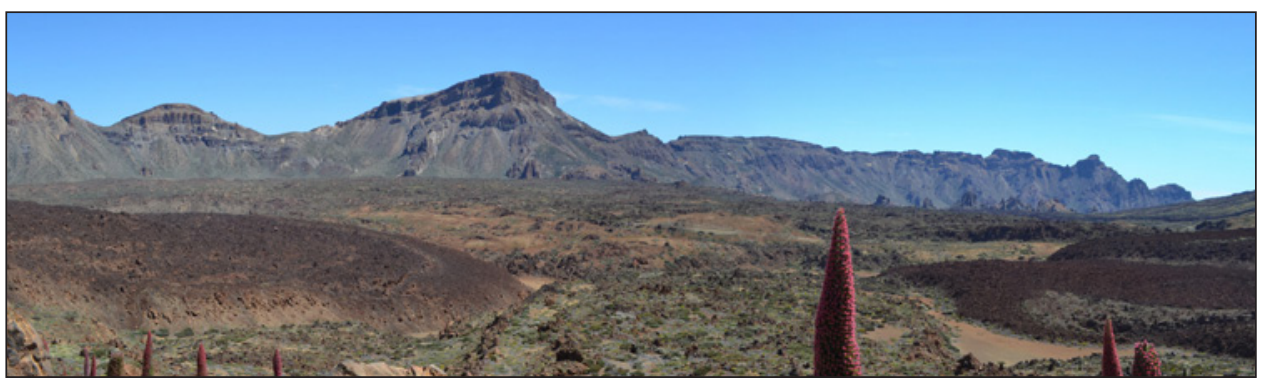

Fuente: autora.

En el interior de este amplio atrio existen, sin embargo, variaciones morfológicas definidas que están en relación no sólo con la particular dinámica eruptiva que las ha generado sino también con la edad de las mismas y con su remodelación erosiva. Destacan así, elementos como el extenso Valle de Ucanca, las coladas pahoehoe iniciales de la formación de Pico Viejo, las amplias laderas lávicas parcialmente tapizadas por materiales detríticos que enlazan sin solución de continuidad con el dorso del estratovolcán, el abanico detrítico de Chafarís o el vasto sector ocupado por los materiales emitidos durante la erupción producida en el S. XVIII, Las Narices del Teide (1798).

Con respecto a la vegetación, en esta unidad de paisaje existe una clara diferenciación entre su sector occidental, con escaso protagonismo de este elemento debido al dominio de los frentes de coladas occidentales más recientes del estratovolcán como las de la erupción de Las Narices del Teide (1798) y el atrio oriental. En este último, la mayor heterogeneidad de materiales se asocia con un matorral abierto dominado por Spartocytisus supranubius, Pterocephalus lasiospermus y/o Adenocarpus viscosus.

\subsection{Teide-Pico Viejo}

Sin embargo, en una primera mirada del parque nacional lo que destaca de forma espléndida en el paisaje es el gran volcán doble de forma cónica, Teide-Pico Viejo, y los numerosos satélites que le rodea y que muestran una extraordinaria diversidad de formas. Es la unidad de paisaje dominada enérgicamente por los procesos constructivos de formas del relieve volcánico y es, asimismo, la gran montaña del archipiélago canario que abandera la primera visión de las islas cuando nos aproximamos a estas latitudes orientales del Atlántico. 
En este panorama principal se descubren múltiples construcciones de origen explosivo y efusivo con variados tipos de edificios y coladas, en los que se reconocen domos y corrientes de lava, arcos de empuje y agujas de protusión petrificadas, conos piroclásticos, cráteres perfectos y vistosos canales lávicos. Todos ellos, además, revestidos de variadas tonalidades, fruto de una bella gradación de colores que van desde el negro al rojo bermejo, pasando por los marrones terrosos, con un resultado fisonómico de una gran belleza (Martínez de Pisón et al. 2008).

Tras la destrucción del edificio Cañadas y la formación de la caldera, la actividad eruptiva, se trasladó espacialmente concentrándose en torno a sólo dos bocas eruptivas y configurando una nueva unidad de paisaje. El estratovolcán Teide-Pico Viejo es resultado de esa traslación y concentración de los procesos de construcción eruptiva en una estrecha franja de disposición paralela a la pared oriental de Las Cañadas, hace unos 179.000 años. Constituye una voluminosa montaña que cubre parcialmente las antiguas estructuras, cerrándolas por el norte; una alta montaña reciente superpuesta a los viejos edificios volcánicos parcialmente desmantelados de Las Cañadas (Figura 4).

\section{Figura 4 \\ VISTA DEL DOBLE ESTRATOVOLCÁN TEIDE-PICO VIEJO DESDE EL VALLE DE UCANCA}

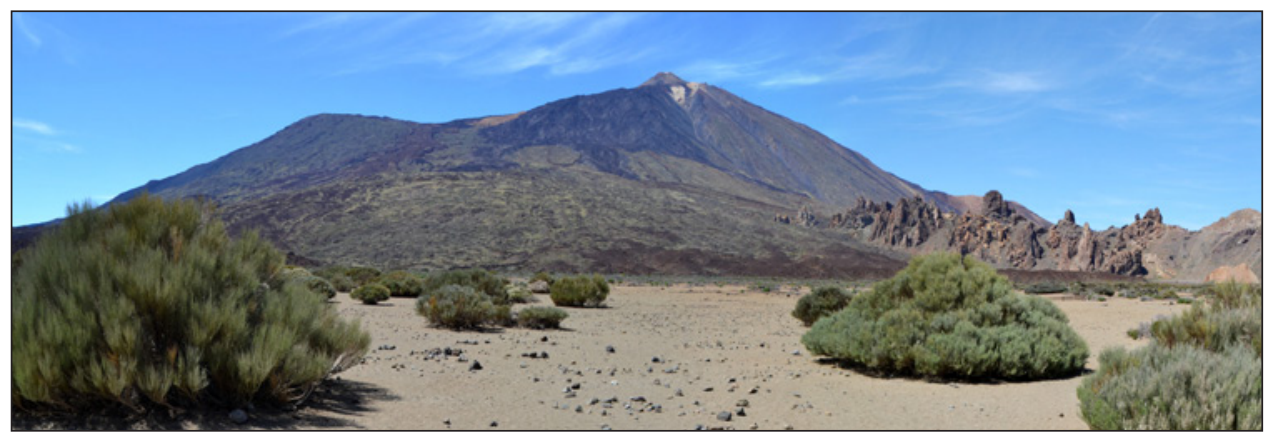

Fuente: autora.

En esta estrecha franja se han concentrado la mayoría de las erupciones volcánicas producidas en los últimos tiempos, primero a través de los dos cráteres principales del estratovolcán: El Teide y Pico Viejo, y luego más tarde, dando lugar a conos volcánicos y a todo un conjunto de domos que orlan su base o rasgan sus flancos. Una historia geológica sencilla con concentración de la actividad en los picos principales primero y más tarde con la construcción de estructuras volcánica menores periféricas.

El estratovolcán del Teide posee los perfiles más soberbios y destacados. Se trata de un edificio de cierta antigüedad con una depresión cratérica culminante oculta en la actualidad. Este gran edificio cónico se caracteriza por laderas acusadas constituidas por el apilamiento de coladas de lava que han perdido ya sus rasgos morfológicos originales, y que muestran signos evidentes de su desmantelamiento en torrentes o en los taludes detríticos que tapizan y homogeneizan las formas volcánicas. 
Una voluminosa montaña que se encuentra, sin embargo, rejuvenecida en su cúspide, en sus flancos y en su base por los materiales emitidos en etapas muy recientes que son los que configuran los elementos morfológicos más destacados del conjunto. Así, rodeando al gran cono en su base, se reconocen los conjuntos de domos coladas recientes de Abejera, Pico Cabras y Los Gemelos, y otros más antiguos y parcialmente sepultados por coladas de mayor juventud, que configuran una unidad espacial de gran originalidad morfológica. También como elemento destacado del conjunto sobresalen el pequeño cono volcánico cimero de El Pitón del Teide y las coladas negras, de marcados rasgos filiformes, que se derraman desde el mismo y cubren casi dos tercios del estratovolcán aunque no llegan prácticamente en ningún caso a sobrepasar los límites del propio edificio.

En contraste con el Teide, Pico Viejo constituye un cono de perfiles y volúmenes menos destacados, de personalidad más sosegada, aunque igualmente rica y rotunda. La mayor juventud geológica de este edificio determina que sus laderas estén constituidas por coladas de lava cuyos rasgos morfológicos de detalle son aún perceptibles, existiendo una elevada variedad morfológica. Sólo hacia el SW y el W, el sistema volcánico histórico de Las Narices del Teide o el contundente y formidable relieve domático de Roques Blancos, respectivamente, introducen elementos morfológicos de primer orden, y también duales, que contribuyen a una mayor diversificación y riqueza del paisaje morfológico.

Esa dualidad se manifiesta incluso en la forma con que ha sido y es percibida la gran montaña de Canarias. Mientras que el Teide está identificado como la alta montaña de las islas, siendo visible desde muchos puntos de Tenerife y desde el Archipiélago, Pico Viejo sólo es percibido como edificio autónomo una vez rebasada la línea de monolitos volcánicos de Los Roques de García o desde puntos muy cercanos al estratovolcán. Sede del infierno y morada de divinidades maléficas como Guayota, el Echeide de los guanches ha sido considerado por los canarios muchas veces como un ente protector y familiar: "el padre Teide", mostrando una vez más la duplicidad de su carácter. Una dualidad, en definitiva, que significa riqueza, contrastes y variedad.

Finalmente, asociado a esta imponente unidad de paisaje del Parque Nacional del Teide, la cubierta vegetal, siempre con una impronta secundaria en la fisonomía general, se organiza en matorrales relativamente cerrados y pluriespecíficos, concentrados en las coladas antiguas del estratovolcán, y los espacios sin vegetación aparente por el sustrato volcánico, que corresponden a una ancha franja de dirección E-W que incluye la mayor parte del Teide, el cráter y norte de Pico Viejo y que se adelgaza en los extremos.

\section{EL TEIDE Y LA VIAJERA OLIVIA STONE}

El libro de viaje de Oliva Stone desprende desde su inicio una atmosfera cultural romántica que atrapa al lector y lo transporta por una experiencia geográfica exquisita, gracias a una perfecta combinación de pasión por la aventura del descubrimiento del paisaje y la cultura de las Islas Canarias con el rigor de su amplia y detallada información sobre el archipiélago, desconocidas en ese momento para la mayor parte de los europeos.

Fascinada por estas islas atlánticas, la viajera victoriana afirma que el archipiélago canario era ya conocido desde los tiempos de Homero, Hesíodo y Píndaro como "Islas Afortunadas" y por Estacio Seboso y Plinio como "Jardín de las Hespérides", locali- 
zando en ellas las islas míticas de los autores griegos y romanos. Inspirada también por ese mismo espíritu romántico las vincula a rutas de piratas y tesoros escondidos, a naufragios, a Colón y al descubrimiento, y se lamenta por el destino de los pobladores originales de las islas, arrasados por la aplastante influencia de los conquistadores españoles. La autora llega a comentar que todo lo que ha leído sobre Canarias, sea realidad o ficción, seduce su imaginación y la transporta a través del espectáculo más salvaje e increíble de los Cuentos de las Mil y Una Noches. No obstante, esa emoción no nubla su formación del XIX y se esfuerza desde el principio de su obra en dejar claro que "ha intentado representar las Islas Canarias tal y como son y cómo las descubrimos en nuestros viajes. Escribí casi todas las descripciones del paisaje, de los hábitos y costumbres, y de los incidentes del viaje en el mismo lugar donde los vi o donde ocurrieron" (Stone, 1995 [ed. orig. 1887]: 9).

Esa voluntad de documentarse con rigor sobre las islas la lleva a consultar los fondos bibliográficos del Museo Británico sobre Canarias antes llevar a cabo su viaje y hace mención de los textos consultados en su cuaderno de viaje destacando, entre otros, el trabajo de Alexander von Humboldt sobre su visita a Canarias, The History of the Discovery and Conquest of the Canary Islands, de George Glas (1764), la traducción de Le Canarien publicada por la Sociedad Hakluyt, primera crónica del s XV de la conquista de Canarias atribuida a los franceses Pierre Bontier y Jean Le Verri y también, Noticias de la Historia general de las Islas de Canarias (1772-1773) del historiador español de la islas, Viera y Clavijo. Como documento cartográfico de consulta permanente durante sus viajes llevará consigo los mapas del Almirantazgo Británico.

Como ya se ha indicado, el gran interés por conocer el archipiélago canario se refleja en la riqueza y el detalle de los contenidos de su publicación y, desde el punto de vista del paisaje natural, objeto principal de análisis de este trabajo, demuestra poseer además una especial sensibilidad hacia la diversidad de sus expresiones y elementos constitutivos más sobresalientes. En este sentido, resulta significativo que a menudo durante sus recorridos por las islas comente con manifiesto entusiasmo la singularidad y belleza del paisaje, así como su sorpresa por los llamativos contrastes que presentan las islas en las que se alternan con frecuencia paisajes fértiles y exuberantes, con tierras desérticas por la sequía o el fuego destructor de los volcanes. Muchas veces, también, más que prendarse por la imagen de los pueblos que visita, eleva su mirada hacia las cumbres isleñas para emocionarse con los volúmenes comprimidos de las montañas que constituyen el corazón de la mayor parte de ellas, y del mismo modo, muestra un especial interés por la flora y los bosques de Canarias de los que alaba sus singularidades naturales, a la vez que denuncia el ritmo atroz de la deforestación de las masas forestales.

Pero en el orden de prioridades que Stone lleva a Canarias está como primera e irrenunciable obligación la visita y el ascenso del Teide. Grabada en su mente está la idea fija de visitar este gran volcán y coronar su cima, además de la convicción que corroborará la experiencia, de que esta elevada montaña constituye el eje geográfico del archipiélago canario. En el barco que la lleva a Tenerife, poco antes de llegar a la isla, escribe: "El día está cubierto y ventoso, sin sol; sólo se percibe su resplandor mientras escudriñamos con nuestros prismáticos y los de todos los demás, intentando atisbar "El Pico”. Para un viajero de cualquier zona del Atlántico, el Pico Teide es por excelencia 
"El Pico". Al mediodía el médico dijo: "¡allí está!. Un coro de "Oh, ¿dónde? en inglés, español, francés, portugués y sueco anunciaba el nerviosísimo latente de todos los que nos encontrábamos a bordo, la lengua materna afirmando su supremacía. (...) El débil perfil gris que primero se transformó en montaña y luego en nubes, resultó más tarde ser sin duda alguna, Tenerife. Las nubes que la cubren y rodean ocultan nuestro El Dorado que, cual belleza altanera, coquetea con los numerosos adoradores que vienen de todas partes a verlo". (Stone, 1995 [ed. orig. 1887] p: 23-24). Llama la atención y es fundamental para confirmar nuestra hipótesis comprobar en sus textos relativos a la visita del Teide, el interés de esta viajera por el paisaje desde un entendimiento global e interrelacionado de sus características más relevantes y su capacidad para organizar los panoramas que contempla con sorprendentes coincidencias con la geografía de sus principales unidades de paisaje.

El sábado 15 de septiembre de 1883, al amanecer, Olivia Stone y su marido John Harris, montados a caballo y acompañados por dos guías de la isla, salen del pueblo de Vilaflor situado en las cumbres meridionales de la isla de Tenerife, a $1.414 \mathrm{~m}$ de altitud, para adentrarse en Las Cañadas del Teide por el pasillo orográfico de Boca Tauce. Estos viajeros entraron por el suroeste del atrio volcánico y realizaron su ruta por el sur de la amplia caldera hacia el sector oriental del estratovolcán del Teide en el que se localizaba el refugio Altavista, lugar del que tradicionalmente se lleva a cabo el ascenso hacia el Pico. Esta visita se realizó, por tanto, fundamentalmente por el sector meridional de Las Cañadas y hacia el este del elemento paisajístico dominante del Teide, lo que condicionó las perspectivas panorámicas del paisaje que la autora contempló que no recorrió la totalidad del área cimera de la isla.

Tras unas horas de recorrido Olivia Stone llega a la vieja caldera volcánica y después de una breve parada para descansar escribe (p. 185): "Aquí, lejos de todo asentamiento humano, en medio de una soledad y silencio perfectos, en una tierra extranjera y acompañada por hombres apuestos y con aspecto de bandidos, aunque realmente honrados y amables, se encontraban dos súbditos ingleses. La cercanía inmediata de una de las maravillas del mundo, la forma inusual de viajar, el aspecto extraordinario del paisaje, el sendero poco habitual y, sobre todo, el saber que caminábamos sobre un cráter, despertaban en nosotros sensaciones que nunca habíamos conocido hasta entonces. El lugar, la memoria y el paisaje se combinaban para inundar la mente con una rica mezcla de fantasía y realidad"

A medida que Olivia Stone se adentra en Las Cañadas del Teide, reconoce con prontitud las dos unidades principales que constituyen este excepcional paisaje cimero de Tenerife. Identifica la amplia caldera volcánica de Las Cañadas como un extenso cráter y en su interior, desplazada hacia el nordeste, el gran estratovolcán del Teide (p. 154): “A nuestros pies se encuentra un estrecho y sinuoso sendero que conduce al fondo del viejo cráter, a Las Cañadas. Pero ante nosotros se encuentra uno de esos paisajes que sobrecoge el alma por su majestuosidad y la abruma por lo increíblemente sublime. Extendiéndose a derecha e izquierda, bajo nosotros, se encuentran Las Cañadas que, desde esta altura, parecen una suave llanura de arena. No hay ningún lugar que iguale a este cráter en ninguna otra parte de nuestro planeta ya que tiene casi ocho millas de diámetro. Nuestros ojos encuentran un obstáculo en el lado opuesto y, alzándolos, descubrimos que el paisaje 
y Las Cañadas están limitados por el Pico Teide, que corona la escena con su asombrosa majestuosidad. Stone avanza hacia el Teide y repite con insistencia la emoción que le produce la visión del paisaje volcánico (p. 155): "Paramos en cada vuelta del sinuoso sendero ya que la grandiosidad del paisaje se vuelve cada vez más sobrecogedora, al aumentar la altura del Teide y de la pared del cráter según descendemos” Sin embargo, esa emoción no perturba su capacidad de interpretar el paisaje a través de los conocimientos científicos del momento señalando, por ejemplo, que el viejo cráter de Las Cañadas ahora dormido hubiera sido en tiempos lejanos una "gigantesca olla que contenía masa fundida hirviente y en movimiento según la intensidad del calor de los fuegos subterráneos". A continuación añade que el pasado de este cráter es el presente del Mauna Loa en las Islas Sandwich, y es capaz de advertir, por ello, distintos momentos o edades geológicas de las dos unidades principales del paisaje.

Pero la viajera victoriana no sólo identifica con claridad la organización espaciotemporal fundamental del paisaje sino que además reconoce formas y elementos del espectacular panorama que contempla. Así, descompone el paisaje en sus constituyentes básicos y hace anotaciones sobre el relieve, la vegetación y el efecto del hombre sobre el territorio, y dentro de éste último, esboza algunas pinceladas sobre el pasado aborigen de este lugar. Toma con frecuencia datos de temperatura a diferentes altitudes ayudada por su termómetro de campo y aneroide, y desde el punto de vista de la vegetación, identifica los individuos florísticos que configuran los rasgos principales del paisaje vegetal en ese momento, señalando que la retama del Teide es la especie dominante (p. 152-153): “descubrí con ávida curiosidad el primer ejemplar de la mundialmente famosa retama del Pico Teide; la altura era de 6000 pies. (...) cuando empezó la retama pensábamos que habíamos dejado atrás el último pino pero estábamos equivocados ya que en medio del valle se alzaba "el último mohicano". (...) El terreno aquí está cubierto de lava y escoria y la forma redondeada y las hojas espirales de la retama, además de alguna cigarra, son las únicas señales de vida (Figura 5.4) El predomino del componente volcánico con sus más variadas formas, apenas veladas por la cubierta vegetal debido al férreo control de las condiciones ambientales, permite que esta viajera pueda disfrutar en su plenitud de la extrema diversidad morfológica y colorística del elemento predominante del paisaje (p. 161): "Sentados a unas yardas sendero arriba, no podíamos dejar de admirar el paisaje que nos rodeaba, por muy árido que fuese, ya que poseía una maravilla de colores". Otro ejemplo de su interés por las formas volcánicas corresponde a este texto (p. 182): “(...) Estas islas interminables de lava, rodeadas por un mar de piedras amarillas, acaban siendo absolutamente fascinantes. A veces, parecían gigantescos jardines de roca, con rincones y grietas suficientes por albergar todos los helechos del universo, pero desprovistos de cualquier hierba, sin siquiera, la más común"

Con respecto a la presencia del hombre en este solitario paraje volcánico, Stone comenta las señales de uso ganadero que experimentaba en esos tiempos Las Cañadas del Teide, y entre ellas destaca la siguiente (p. 158): "En esta región desértica nos encontramos, de repente, con una minúscula choza, construida con trozos de lava junto a un río de lava. El dueño, un pastor, se encontraba de pie delante de ella, interesado y curioso por ver a los que invadían su feliz dominio. Era tan alto, recto y atractivo 
que podría haber sido un guanchel, aunque iba con poca ropa. Podíamos imaginarnos el último guanche así huido, con toda la dignidad y desesperación de la que era capaz esa noble raza, esperando a sus perseguidores. En otro párrafo comenta (p.155): "Nos sentamos a la sombra de una roca a comer algo de fruta mientras los animales descansan, se alimentan y beben en el "Manantial de Guajara”. Este manantial es la única agua en toda la zona de Las Cañadas y, como tal, es valiosísima para el viajero de aquellos parajes solitarios. Sin embargo, sus visitantes más frecuentes son las cabras y los pájaros.”

Las visiones del paisaje de Las Cañadas y El Teide, y el intento de aproximarse a las relaciones que se puedan establecer entre sus constituyentes quedan reflejadas a través de esta selección de textos. Pero una lectura más afinada del mismo descubre otras variables geográficas en su caracterización que tienen que ver con la capacidad de la autora para llevar a cabo, además, diversas descripciones a variadas escalas, hábilmente hilvanadas, que hacen de su prolija redacción una acertada síntesis de la complejidad geográfica de esta original montaña subtropical. Así, una vez que introduce en las unidades principales y en sus rasgos más sobresalientes pasa a describir algunos de los mundos menores que atesoran cada una de ellas. Por ejemplo, en Las Cañadas identifica otras expresiones que diversifican localmente la configuración de la caldera volcánica (p.155): “Ahora nos damos cuenta de que, Las Cañadas, que antes nos parecían una superficie totalmente plana, cuya piedra pómez, cual arena movida por la bajamar, había quedado lisa y uniforme, en realidad están resquebrajadas y recorridas en varios lugares por colinas bajas y montículos de lava roja. (...). Estas colinas, altillos, o montículos están formadas por rocas rojas muy escabrosas; en realidad parece que sólo tengan aristas. La lava está entremezclada con el verdigrís de los redondos arbustos de retama, de color y forma similar a la lavanda pero más ásperos". O este otro texto en el que se detiene a describir uno de los elementos vertebradores del paisaje interior de Las Cañadas (p.188-189): "Los Roques son unas masas de lava altas, puntiagudas y afiladas, surgidas en época pasadas cuando el cráter estaba enfriando y que no volvieron a hundirse sino que permanecieron como una especie de recordatorio de lo que había ocurrido. Desde lejos parecen ruinas de un castillo, y lo son-las ruinas de un castillo de lava-. Se corresponden con las chimeneas temporales que se elevan de entre la hirviente lava en Hawai, descritas por la Srta. Bird" (Figura 5.1).

Del mismo modo, en el Teide realiza un esmerado reconocimiento de su aspecto que le lleva a revelar algunos de sus elementos menores más llamativos como el domo volcánico de Montaña Blanca o las Piedras Negras de grandes dimensiones, como gigantes "bombas volcánicas", que aparecen situadas en la base del gran volcán (Figura 5.2). El pico del Teide lo describe de esta forma antes de iniciar su escalada (p.156): "la panorámica del Pico desde aquí incluye el corte de un cráter que todo cráter tiene en el lado que nunca sopla el viento y que por consiguiente, no recibe la lluvia de ceniza y brasas. (...) Los ríos de lava que bajan hacia la llanura de Las Cañadas destacan claramente” (Figura 5.3).

1 Los guanches fueron los antiguos habitantes de Tenerife hasta su desaparición como pueblo después de la conquista de las islas por la Corona de Castilla a finales del s. XV. Su origen se relaciona con las tribus bereberes que vivieron en el norte de África. 


\section{Figura 5}

\section{ALGUNOS ELEMENTOS DEL PAISAJE DEL TEIDE A ESCALA LOCAL RECONOCIDOS POR OLIVIA STONE}
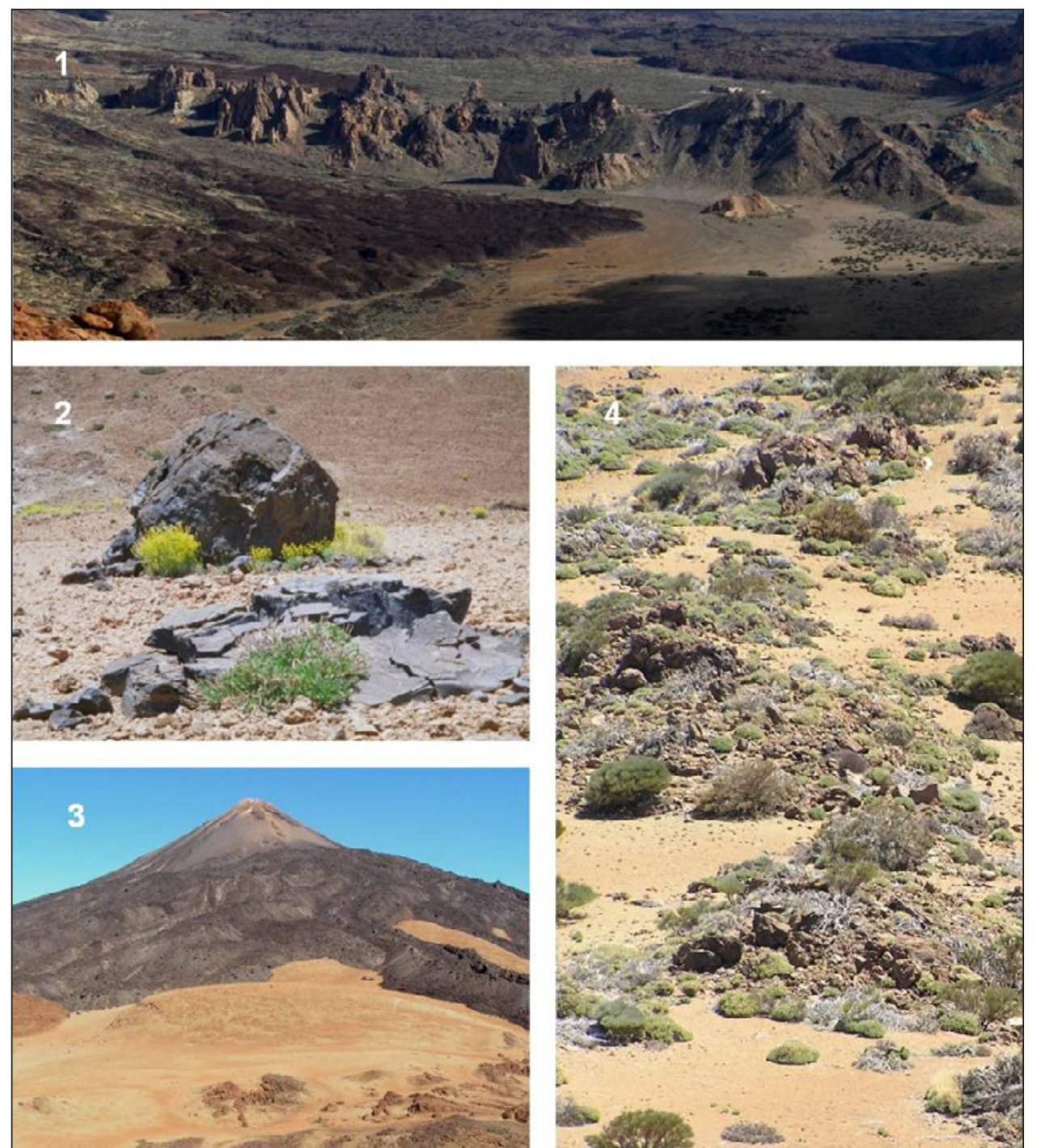

Fuente: autora.

Después de que el grupo de excursionistas superara el nerviosismo de la desorientación en su intento de avanzar por el extenso e intrincado mar de coladas de lava de Las Cañadas orientales, que llega incluso a poner en peligro el destino principal de la visita, logran montar su pequeño campamento al caer la tarde en la base del Teide para recobrar 
fuerzas. De madrugada emprenden el ascenso al pico y Olivia Stone describe de nuevo las difíciles condiciones que ofrecía el sustrato volcánico para alcanzar la cima (p. 167168): "Hacía un frío intenso y cada uno se había envuelto en una manta, aparte de las chaquetas y abrigos que llevábamos. La luna, lo más luminosa y llena posible, brillaba sobre nosotros y, ayudados y deslumbrados a la vez por su luz, trepamos por la lava. Mi traje de montar resultó muy útil ya que remangándome el vestido como hacen las pescadoras podía saltar de risco en risco. (...) Es muy poco seguro avanzar rápidamente o meramente avanzar. La lava es una masa no sólo desigual sino también escabrosa. Tiene hondonadas y hendiduras además de ser muy irregular. Las rocas de lavas de un grosor de entre unos pocos pies y varios cientos de pies cúbicos, están amontonadas de cualquier manera, sin que haya dos de igual forma o tamaño. Con gran dificultad subimos, bajamos y saltamos por ella". (...) Como llevábamos a cabo esta actividad, tan parecida a la de los gamos, a la luz de la luna y no a la del sol, había cierto grado de nerviosismo y una deliciosa incertidumbre sobre cuál sería el lugar donde aterrizaríamos a continuación. Al principio, cuando empezamos a subir, teníamos que gritar "Alto" cada pocos minutos para recobrar el aliento, debido, creo, más al aire enrarecido que al esfuerzo que, aunque era bastante vigoroso, no era realmente algo que te dejara sin aliento".

A partir de los fragmentos de textos seleccionados, se percibe una manera de mirar de Olivia Stone el escenario del Teide con sentido de reunión, de configuraciones y visiones globales del paisaje pero también, la observación del paisaje-forma se filtra además, no sólo por niveles de conocimiento y de cultura, sino también de sensibilidad y por categorías morales de relación con nuestros escenarios ( $c f$. Martínez de Pisón, 2009b). Esta viajera inglesa supo vivir la experiencia del descubrimiento del paisaje no sólo como una observación global y directa del mismo sino además como una experiencia vital que hizo de su circunstancia geográfica algo todavía más extraordinaria y porque no decirlo, sublime. Stone al coronar el Teide a la salida del sol escribió (p.174): “La pobreza de las palabras se evidencia con fuerza cuando el corazón late, el pulso palpita y la cara muestra las emociones que provocan el esfuerzo inútil, absolutamente inútil por dibujar con el lenguaje adecuado la gloriosa e irresistible majestad de la naturaleza. Parece como si necesitase el canto armonioso y grandioso de todos los coros del cielo y la tierra, acompañados por instrumentos y voces desconocidas y nunca escuchadas por el hombre para encauzar completamente las salvajes y apasionadas expresiones a las que el corazón querría gustosamente dar rienda suelta. Uno de los logros más sublimes de la naturaleza, donde todos sus vastos recursos se unen para ofrecer un efecto grandioso y supremo, es un amanecer visto desde el Pico del Teide".

A través de la lectura de estos fragmentos del texto, resulta fácil entender cómo la publicación de su cuaderno de viaje tuvo tanta aceptación entre el público inglés, ansioso de aventuras y descubrimiento de la belleza salvaje de estos exóticos paisajes volcánicos insulares de la costa noroccidental africana.

\section{CONCLUSIONES}

Por medio de la consecución del doble objetivo de este trabajo se ha podido comprobar la viabilidad del concepto geográfico del paisaje natural como recurso turístico, que ya 
constituía un objeto de atracción significativo para los turistas que visitaban Canarias a finales del XIX. Un concepto basado en una manera de mirar la naturaleza con perspectiva global o de conjunto, más cercano a la identidad de los territorios, y que el turista busca y demanda generalmente con más interés que la visión exclusiva de sus elementos constituyentes aislados, como la geología, la flora y la fauna. Por tanto, este recurso no se puede presentar como una novedad turística de la actualidad, ya que existía en las élites europeas cultas y exigentes, con una elevada sensibilidad hacia el descubrimiento de las originalidades paisajísticas de los lugares de destino. La elección de muchos de sus viajes se relacionaba con la búsqueda de paisajes singulares y exóticos, muy alejados de lo habitual y conocido en sus lugares de origen. Ambos realidades avalan la recuperación, por tanto, de este recurso turístico como alternativa de calidad en una etapa de segunda generación, agotado el modelo de sol y playa, al que se enfrenta los nuevos retos turísticos en Canarias. Unas islas que destacan precisamente a escala mundial por la riqueza de sus paisajes.

Por otra parte, el estudio de las inquietudes culturales de la viajera Olivia Stone por el descubrimiento de estas islas permite definir a un turista de calidad, con espíritu aventurero, que visitaba Canarias y que debemos considerar como indudable referencia para rediseñar una forma de hacer turismo en Canarias, capaz de consolidar la oferta y "fidelizar" su visita al archipiélago canario.

\section{BIBLIOGRAFÍA}

AMADOR, J.S. (2005): “Introducción”. En STONE, O. [ed. orig. 1887]): El planeta Tenerife. Santa Cruz de Tenerife, Idea.

ANCOCHEA, E., FUSTER, J.M. IBARROLA, E. COELlo, J., HERNÁN, F., CENDRERO, A., CANTAGRELL, J.M. y JAMOND, C. (1989): "La edad del Edificio Cañadas". En ARAÑA, V. y COELLO, J. (eds.): Los volcanes y la caldera del Parque Nacional del Teide (Tenerife, Islas Canarias). Madrid, ICONA, pp. 315-320.

BELTRÁN, E. (2000): Los volcanes históricos de Tenerife como unidades de paisaje. Las Palmas de Gran Canaria, Fundación Canaria Mapfre-Guanarteme.

BERTRAND, C. y BERTRAND, G. (2006 [ed. orig. 2002]): Geografía del Medioambiente. Granada, Editorial Universidad de Granada.

CLEASBY J. (1889): Gran Canary: its climate and springs. London, John Richardson Leicester.

DURBAN, M. y REVERÓN, J. (coord.) (2011): El Parque Nacional del Teide: Inscripción en la Lista del Patrimonio Mundial. Naturaleza y Parques Nacionales. Madrid, Organismo Autónomo de Parques Nacionales.

GONZÁLEZ CRUZ, C. (2000) “Introducción”. En SMALER BROWN. A. (2000 [ed. orig. 1919]): Madeira, Islas Canarias y Azores. Las Palmas de Gran Canaria, Cabildo de Gran Canaria.

GONZÁLEZ LEMUS, N. (1998): Viajeros victorianos en Canarias. Imágenes de la sociedad isleña en la prosa de viajes. Las Palmas de Gran Canaria, Ediciones del Cabildo Insular de Gran Canaria. 
GONZÁLEZ LEMUS, N.; GONZÁLEZ MORALES, A.; HERNÁNDEZ LUIS, J. A.; NAVARRO MARCHANTE, V. (2012): Evolución histórica y geográfica del viaje y del Turismo en Canarias. Madrid, Anroart Ediciones.

GROS, C. (2002): "La relación paisaje-turismo-desarrollo local: revisión de su significado en publicaciones. Promociones recientes Divulgación Territorial", Revista de Desarrollo Rural y Cooperativismo Agrario, ${ }^{\circ}$ 6, pp. 123-133.

HERNÁNDEZ MARTÍN, R. y SANTANA, A. (Coord.) (2010): Destinos turísticos maduros ante el cambio. Reflexiones desde Canarias. Instituto universitario de Ciencias Políticas y Sociales. Universidad de La Laguna.

HOWARTH, O.S.R. e. al. (1911): "London", en Encyclopedia Britannica, nº16, pp. 938968.

MARTÍNEZ DE PISÓN, E., AROZENA, M.E., BELTRÁN, E. y ROMERO, C. (2008): "El paisaje como criterio de valoración territorial. El Parque Nacional del Teide (Tenerife, Islas Canarias)". Turismo, Revista de estudios de turismo de Canarias y Macaronesia, ${ }^{\circ} 0$, pp. 155-178.

MARTÍNEZ DE PISÓN, E. (2009a): "Los paisajes de los geógrafos”, Revista Geographicalia, $\mathrm{n}^{\circ}$ 55, pp. 5-25.

MARTÍNEZ DE PISÓN, E. (2009b): Miradas sobre el paisaje. Madrid, Biblioteca Nueva.

MARTÍNEZ DE PISÓN, E., AROZENA, M.E., BELTRÁN, E. y ROMERO, C. (2009): Los paisajes del Parque Nacional del Teide. Madrid, Organismo Autónomo Parques Nacionales.

MARTÍNEZ DE PISÓN, E., AROZENA, M.E., BELTRÁN, E. y ROMERO, C. (2011): "El paisaje", en DURBAN Mm y REVERÓN J. (coord.). El Parque Nacional del Teide: Inscripción en la Lista del Patrimonio Mundial. Madrid, Organismo Autónomo de Parques Nacionales, pp. 263-344.

MURRAY, E. (1988 [Ed. Orig. 1859]): Recuerdos de Gran Canaria y Tenerife. Santa Cruz de Tenerife, Pedro Duque Canarias.

NOGUÉ, J. (1989): "Paisaje y turismo", Revista Estudios Turísticos. Instituto de Estudios Turísticos. Ministerio de Economía y Competitividad, Gobierno de España, no 103, pp. 35-46.

RIEDEL, U. (1972): "Las líneas de desarrollo del turismo en las Islas Canarias". Anuarios de Estudios Atlánticos, Cabildo insular de Gran Canaria, vol. I, nº 18, pp. 491-533.

SMALER BROWN, A. (2000 [ed. orig. 1919]): Madeira, Islas Canarias y Azores. Las Palmas de Gran Canaria, Cabildo insular de Gran Canaria.

STONE, O. (1995 [ed. orig. 1887]): Tenerife y sus seis satélites. 2 Tomos. Las Palmas de Gran Canaria, Cabildo Insular de Gran Canaria.

VILLALBA, E. (1999): "El Teide, un parque turístico", en El Territorio y su imagen, vol. II. Actas del XVI Congreso de Geógrafos Españoles. Málaga, Departamento de Geografía de la Universidad de Málaga, pp. 737-746. 
